\section{Kidney Blood Pressure Research}

\title{
Association of Intradialytic Hypertension with Left Ventricular Mass in Hypertensive Hemodialysis Patients Enrolled in the Blood Pressure in Dialysis (BID) Study
}

\author{
Amith Roy Shamira Ameet Karembelkarb Jonathan Yabes ${ }^{c} \quad$ Yi Yao $^{c}$ \\ Dana Miskulin $^{d}$ Jennifer Gassman ${ }^{\mathrm{e}}$ David Ploth ${ }^{f}$ Lavinia Negrea ${ }^{g}$ Susan Paine ${ }^{h}$ \\ Mahboob Rahmang Raymond Y. Kwong ${ }^{i} \quad$ Philip Zager $^{\text {h.j }} \quad$ Manisha Jhamb \\ aRenal-Electrolyte Division, Department of Medicine, University of Pittsburgh, Pittsburgh, PA, bPrivate \\ Nephrology Practice, Pittsburgh, PA, 'Center for Research on Heath Care, Division of General \\ Internal Medicine, Department of Medicine and Biostatistics, University of Pittsburgh, Pittsburgh, PA, \\ dNephrology Division, Department of Medicine, Tufts University, Boston, MA, eQQuantitative Health \\ Sciences Department, Cleveland Clinic, Cleveland, $\mathrm{OH}$, ${ }^{\mathrm{N}}$ Nephrology Division, Department of Medicine, \\ Medical University of South Carolina, Charleston, SC, ${ }^{9}$ Nephrology and Hypertension Division, \\ Department of Medicine, Case Western Reserve University, Cleveland, $\mathrm{OH}$, hDialysis Clinic, Inc., New \\ Mexico, NM, 'Cardiovascular Division, Department of Medicine, Harvard Medical School, Boston, MA, \\ jNephrology Division, Department of Medicine, University of New Mexico, NM, USA
}

\section{Key Words}

Intradialytic hypertension • Hemodialysis • Left ventricular mass

\begin{abstract}
Background/Aims: Intradialytic hypertension (IDH), or paradoxical rise in blood pressure (BP) during hemodialysis (HD) is associated with increased morbidity and mortality. The association between IDH and increased left ventricular mass (LVM), a well-known risk factor for adverse cardiovascular outcomes in HD patients, has not been studied. The aim of our study is to evaluate the cross-sectional association of intradialytic change in BP with cardiac structure and function measured by cardiac MRI in hypertensive HD patients enrolled in the multi-center Blood Pressure in Dialysis (BID) clinical trial. Methods: Participants in the BID study were categorized into 3 groups based on average change $(\Delta)$ in systolic blood pressure (SBP) (post-HD SBP minus pre-HD SBP) during HD over a 1 month period: group 1 - patients with an increase in SBP $\geq 10 \mathrm{~mm} \mathrm{Hg}$ during HD (IDH); group 2 -patients with SBP decrease of greater $\geq 10 \mathrm{~mm} \mathrm{Hg}$ during HD; group 3 - patients with SBP increase or decrease by $<10 \mathrm{~mm}$ Hg during HD. LVM index (LVMI) was measured using cardiac MRI, which were centrally read.
\end{abstract}

Manisha Jhamb, MD MPH

Assistant Professor of

Medicine
Renal-Electrolyte Division, University of Pittsburgh School of Medicine

200 Lothrop St, PUH C-1101, Pittsburgh PA 15213 (USA)

Tel. +1-412-647-7062, Fax +1-412-802-6852, E-Mail jhambm@upmc.edu 


\section{Kidney \\ Blood Pressure Research}

Kidney Blood Press Res 2018;43:882-892

\begin{tabular}{l|l}
\hline DOI: $10.1159 / 000490336$ & (c) 2018 The Author(s). Published by S. Karger AG, Basel
\end{tabular}

Published online: 5 June, 2018

www.karger.com/kb

Baseline characteristics were compared in the 3 groups and multivariable regression models were fitted for the adjusted association of IDH with LVMI. Results: Among the 80 participants, 7 (8.8\%) had IDH and had average $\triangle$ SBP $17.0 \pm 10.1 \mathrm{mmHg}$ during HD. Patients with IDH were less likely to be diabetic, had lower pre-dialysis SBP and lower percent interdialytic weight gain as compared to the other 2 groups ( $p=0.02, p<0.001$ and $p=0.02$ respectively). In multivariable regression analyses, IDH was significantly associated with LVMI (adjusted mean difference relative to SBP decreased group $[95 \%$ confidence interval $(\mathrm{CI})]=12.5[3.6,21.5], p=0.01)$ after adjusting for age, sex, diabetes, IDWG\%, pre-HD SBP and beta blocker use. Every $1 \mathrm{~mm}$ rise in $\triangle$ SBP during HD was associated with $0.2 \mathrm{~g} / \mathrm{m}^{2}$ increase in LVMI in adjusted models $(p=0.04)$. Conclusion: IDH is independently associated with higher LVMI in hypertensive HD patients and may contribute to increased cardiovascular events.

(C) 2018 The Author(s)

Published by S. Karger AG, Basel

\section{Introduction}

The majority of hemodialysis (HD) patients experience a decline in blood pressure (BP) during HD treatment. However, there is a subset of patients that have a recurrent and paradoxical rise in BP during HD. This phenomenon of increase in BP from pre-post HD, known as intradialytic hypertension (IDH), occurs in approximately $10-15 \%$ of the patients [1-3]. No standard definition of IDH exists, but has most commonly been defined as $\geq 10 \mathrm{mmHg}$ rise in systolic BP (SBP) during dialysis. IDH has been associated with poor clinical outcomes in HD patients including increased hospitalizations, higher ambulatory BP, cardiovascular morbidity, and mortality [4-6].

How IDH leads to adverse cardiovascular events is not known. Pathophysiological mechanisms underlying IDH such as extracellular volume overload, sympathetic overactivity, endothelial dysfunction, sodium loading from dialysate and/or clearance of anti-hypertensive medications during HD may contribute to increased cardiovascular risk in these patients [1, 7-11]. It is also plausible that IDH, directly or indirectly leads to increased left ventricular mass (LVM), a well-known risk factor for adverse cardiovascular outcomes in HD patients [12].

The aim of this study is to evaluate the cross-sectional association of intradialytic change in BP with cardiac structure and function measured by cardiac MRI in hypertensive HD patients enrolled in the Blood Pressure in Dialysis (BID) study [13]. We hypothesized that an increase in systolic blood pressure during dialysis (IDH) is associated with increased left ventricular mass index (LVMI) in HD patients.

\section{Materials and Methods}

\section{Study Population}

Blood Pressure in Dialysis (BID) is a multi-center pilot randomized clinical trial with the goal of assessing feasibility and safety of treating chronic HD patients to a standardized (155-165 $\mathrm{mm} \mathrm{Hg}$ ) versus intensive (110-140 mm Hg) pre-dialysis SBP target over 1 year period (Clinicaltrials.gov NCT01421771) [13]. Eligibility criteria included age $\geq 18$ years, on maintenance HD $\geq 3$ months, upper arm suitable for measuring blood pressure, and a predialysis SBP $\geq 155 \mathrm{~mm} \mathrm{Hg}$ or anticipated to rise to $\geq 155 \mathrm{~mm} \mathrm{Hg}$ after backtitration of antihypertensive drugs. Exclusion criteria included unscheduled dialysis treatments for congestive heart failure, intradialytic hypotension requiring hospitalization or contraindication for cardiac MRI. For this cross-sectional analysis, the subset of BID participants who had available baseline cardiac MRI data and dialysis unit BP data for at least $80 \%$ of treatments in 1 month prior to BID enrollment were included. All participants provided written, informed consent and the study was approved by each site's Institutional Review Board. 


\section{Kidney Blood Pressure Research}

\section{Intradialytic Hypertension (IDH)}

Routine seated pre-HD and post-HD BP values were measured during every HD session by means of automatically inflated cuffs using a digital monitor attached to each HD machine according to standard dialysis unit protocols, and were captured electronically within the databases. All available pre- and postHD BP measurements for 1 month prior to BID enrollment were included. We used pre-enrollment BPs rather than BPs during baseline period of BID study as the antihypertensive medications may have been adjusted during baseline period to achieve a 2-week average predialysis SBP $\geq 155 \mathrm{~mm} \mathrm{Hg}$ as per the BID study protocol. Changes $(\Delta)$ in systolic BP, defined as post-HD SBP minus pre-HD SBP, were averaged for each patient. Patients were stratified into three groups; group 1 - patients with an increase in SBP $\geq 10 \mathrm{~mm}$ Hg during HD (IDH); group 2 -patients with SBP decrease of greater $\geq 10 \mathrm{~mm} \mathrm{Hg}$ during HD; group 3 patients with SBP increase or decrease by $<10 \mathrm{~mm} \mathrm{Hg}$ during HD. Group 1 represents IDH based on existing definitions of increase in SBP $\geq 10 \mathrm{~mm} \mathrm{Hg}$ [1].

\section{Cardiac structural and functional measures}

Cardiac MRI was done during the baseline period on a non-dialysis day using a standardized protocol. All MRIs were read centrally by the Core Lab in Brigham and Women's Hospital by a single cardiologist (RK). The main outcome of interest was left ventricular mass index (LVMI) at baseline. It was calculated as LVM/ (height^2.7), where height is in meters [14]. Left ventricular hypertrophy (LVH) was defined as LVMI $\geq 45$ $\mathrm{g} / \mathrm{m}$-height for women and $\geq 49 \mathrm{~g} / \mathrm{m}$-height for men based on established guidelines [15]. Other functional cardiac parameters such as left ventricular end-systolic volume (LVESV) and left-ventricular end-diastolic volume (LVEDV) were also obtained. Ejection fraction was calculated as (LVEDV-LVESV)/LVEDV x 100. Given that, geometry of left ventricular hypertrophy, specifically increased left ventricular concentricity, is a reflection of diastolic dysfunction, we evaluated LV concentricity [16, 17]. LV concentricity was defined as LV mass/LVEDV ^ 0.67 and compared among the 3 groups [17]. Also, the percentage of patients with concentric hypertrophy in each group were calculated using predefined thresholds - concentricity $\geq 8.1 \mathrm{~g} /$ $\mathrm{mL}^{0.67}$ (women) and $\geq 9.1 \mathrm{~g} / \mathrm{mL}^{0.67}$ (men) [17].

\section{Socio-demographic, Disease, and Treatment Specific Factors}

Socio-demographic data including patients' age, gender, race, ethnicity, comorbidity data, medication data, and laboratory values were gathered from the patients' medical record. Antihypertensive medications were classified as dialyzable or non-dialyzable based on published literature [11]. Dialysis treatment specific data including prescribed dialysate sodium, dialysate calcium, estimated dry weight (EDW) and interdialytic weight gain (IDWG) were obtained from dialysis records. Interdialytic weight gain (averaged for dialysis sessions over 1 month) was calculated as the average change in weight between dialysis sessions. Percent interdialytic weight gain (IDWG\%) was calculated as the average interdialytic weight gain divided by the postdialysis weight averaged over 1 month. Dialysate serum sodium gradient was calculated as the prescribed dialysate sodium minus predialysis serum sodium. Dialysate serum calcium gradient was calculated as dialysate calcium minus predialysis serum calcium. For these calculations, average of all dialysate and serum electrolyte values over 1 month were used.

\section{Statistical Analysis}

Descriptive summaries for patient characteristics were presented using means and standard deviations (SD) for continuous variables; and frequencies and percentages for categorical variables. Bivariate associations with the $3 \triangle \mathrm{SBP}$ groups were assessed using ANOVA and Chi-square or Fisher exact test depending on the variable type. To examine crude correlations between continuous variables, scatter plots with LOWESS curve and Spearman correlation coefficients were used. Unadjusted and adjusted linear regression models were fitted to examine the relationship between $\triangle \mathrm{SBP}$ and cardiac MRI measures (LVMI). Our primary analysis used LVMI as outcome and $\triangle \mathrm{SBP}$ group as predictor. We also examined $\Delta$ SBP as a continuous variable. We adjusted for potential confounders selected based on clinical reasons rather than statistical and accounting for the limited sample size. 


\section{Kidney Blood Pressure Research}

\section{Sensitivity Analyses}

Since IDH has also been defined as systolic BP increase $\geq 10 \mathrm{mmHg}$ from pre- to post hemodialysis in at least four of six treatments [4], we used this definition to do sensitivity analysis in our study. Additionally, we also calculated the proportion of dialysis treatments for each individual patient with $\Delta \mathrm{SBP} \geq 10 \mathrm{mmHg}$. We evaluated whether the proportion of dialysis treatments with IDH were associated with LVMI. The proportion was examined both as continuous and categorical covariate. We categorized it using 25\%, 50\% and $75 \%$ as predetermined cut-offs.

Statistical analyses were carried out using R (version 3.3.3) using the packages dpylr for data manipulation, compareGroups for descriptive tables, rms for modeling, segmented for change-point estimation, and ggplot2 for plotting [18-20] .

\section{Results}

The distribution of average $\triangle \mathrm{SBP}$ during HD is shown in Fig. 1. Among the 80 hypertensive HD patients studied, 7 patients (8.8\%) had IDH i.e. average $\Delta$ SBP $\geq 10 \mathrm{mmHg}$ during HD (Group 1). Forty patients ( $50 \%$ ) had an average $\Delta \mathrm{SBP} \geq-10 \mathrm{mmHg}$ (Group 2) and 33 patients (41.3\%) had $\Delta$ SBP $<10 \mathrm{~mm} \mathrm{Hg}$ (Group 3). In the IDH group, the median of percentage of treatments in which $\triangle \mathrm{SBP}$ during $\mathrm{HD}$ was $\geq 10 \mathrm{mmHg}$ was $50 \%$ [interquartile range $44 \%$, $62 \%]$.

\section{Baseline characteristics}

The baseline characteristics of the 3 groups are shown in Table 1. The 3 groups were similar in age, sex, race and dialysis vintage. Patients in IDH group were significantly less likely to be diabetic than the other groups $(p=0.02)$ but there were no differences in other comorbidities including congestive heart failure, coronary artery disease or peripheral vascular disease. Interestingly, patients in IDH group had lower pre-dialysis systolic BP (SBP) and lower IDWG\% as compared to the other 2 groups ( $\mathrm{p}<0.001$ and $\mathrm{p}=0.02$ respectively). There was a significant moderate negative correlation between pre dialysis SBP and $\triangle$ SBP, such that those with higher pre dialysis SBP had lesser increase in $\triangle$ SBP during HD (spearman correlation $r=-0.59, \mathrm{p}<0.001$ ).

There were no differences between the groups in terms of number or class of antihypertensive medications, except for beta-blocker use, which was much lower in the group 2. There was also no difference in dialyzable antihypertensive medications use among the 3 groups. There were no significant differences in laboratory parameters among the 3 groups. There were no significant differences in dialysate sodium, dialysate calcium and dialysate serum sodium or calcium gradients in the 3 groups. We did observe a weak positive correlation between dialysate serum calcium gradient and $\triangle \mathrm{SBP}$ during $\mathrm{HD}$ (spearman correlation $r=0.35$, $p=0.002$ ).

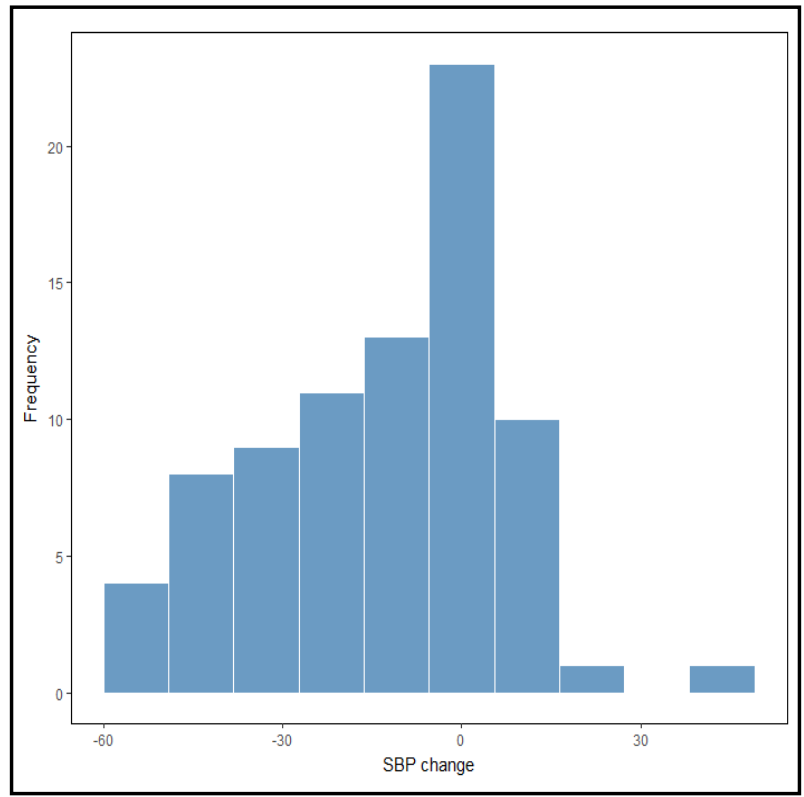

Fig. 1. Distribution of average change in systolic blood pressure during dialysis. 


\section{Kidney Blood Pressure Research}

Table 1. Baseline Characteristics of HD patients according to average change is SBP during HD

\begin{tabular}{|c|c|c|c|c|}
\hline Variable & $\begin{array}{c}\text { SBP Increased } \geq 10 \mathrm{mmHg} \\
(\mathrm{N}=7) \\
\text { Mean (SD) or } \mathrm{n}(\%) \text { or median } \\
{\left[25^{\text {th }}, 75^{\text {th }} \text { quartile }\right]}\end{array}$ & $\begin{array}{c}\text { SBP Decreased } \geq 10 \mathrm{mmHg} \\
(\mathrm{N}=40) \\
\text { Mean (SD) or } \mathrm{n}(\%) \text { or median } \\
{\left[25^{\text {th }}, 75^{\text {th }} \text { quartile] }\right.}\end{array}$ & $\begin{array}{c}\text { SBP Unchanged }+/-10 \mathrm{mmHg} \\
(\mathrm{N}=33) \\
\text { Mean (SD) or } \mathrm{n}(\%) \text { or median } \\
{\left[25^{\text {th }}, 75^{\text {th }} \text { quartile }\right]}\end{array}$ & $P$ value \\
\hline Age (yrs.) & $50(11.5)$ & $56.2(11.5)$ & $57.5(12.1)$ & 0.32 \\
\hline Male (\%) & $6(85.7 \%)$ & $20(50.0 \%)$ & $20(60.6 \%)$ & 0.23 \\
\hline Race: & & & & 0.35 \\
\hline Black (\%) & $3(42.9 \%)$ & $14(35.0 \%)$ & $12(36.4 \%)$ & \\
\hline White (\%) & $2(28.6 \%)$ & $21(52.5 \%)$ & $15(45.5 \%)$ & \\
\hline Other (\%) & $2(28.6 \%)$ & $4(10.0 \%)$ & $6(18.2 \%)$ & \\
\hline Hispanic Ethnicity (\%) & $2(28.6 \%)$ & $18(45.0 \%)$ & $12(36.4 \%)$ & 0.70 \\
\hline Dialysis vintage (years) & $2.4[1.2,5.2]$ & $3.5[1.8,5.8]$ & $2.4[0.8,3.8]$ & 0.17 \\
\hline Diabetes & $2(28.6 \%)$ & $32(80.0 \%)$ & $21(63.6 \%)$ & 0.02 \\
\hline Congestive Heart Failure & $0(0.0 \%)$ & $5(12.5 \%)$ & $6(18.2 \%)$ & 0.63 \\
\hline Cardiovascular Disease & $0(0.0 \%)$ & $3(7.5 \%)$ & $3(9.1 \%)$ & 1.00 \\
\hline Peripheral Vascular Disease & $0(0.0 \%)$ & $5(12.5 \%)$ & $3(9.1 \%)$ & 0.60 \\
\hline EDW (Kg) & $68.5(11.8)$ & $78.2(18.1)$ & $71.8(17.6)$ & 0.19 \\
\hline IDW gain $(\mathrm{Kg})$ & $2.0(1.0)$ & $3.0(1.0)$ & $2.2(1.0)$ & 0.001 \\
\hline IDWG\% & $3.0(1.5)$ & $3.9(1.3)$ & $3.1(1.5)$ & 0.02 \\
\hline Pre-dialysis SBP (mm Hg) & $149(7.7)$ & $171(15.3)$ & $156(14.5)$ & $<0.001$ \\
\hline Pre-dialysis DBP (mm Hg) & $83.9(9.4)$ & $86.4(12.1)$ & $82.4(13.3)$ & 0.38 \\
\hline Post-dialysis SBP (mm Hg) & $166(7.9)$ & $141(15.7)$ & $155(14.2)$ & $<0.001$ \\
\hline Post-dialysis DBP (mm Hg) & $88.9(6.8)$ & $73.8(9.5)$ & $81.3(11.1)$ & $<0.001$ \\
\hline $\begin{array}{l}\text { Average change in SBP during } \\
\mathrm{HD}(\mathrm{mm} \mathrm{Hg})\end{array}$ & $17.0(10.1)$ & $-29.4(14.1)$ & $-0.8(5.1)$ & $<0.001$ \\
\hline No. of antihypertensive meds & $2.7(0.8)$ & $2.5(1.6)$ & $3.1(1.1)$ & 0.26 \\
\hline RAAS Blockade (\%) & $3(50.0 \%)$ & $23(57.5 \%)$ & $19(59.4 \%)$ & 0.94 \\
\hline Beta-blocker & $5(83.3 \%)$ & $24(60.0 \%)$ & $31(96.9 \%)$ & $<0.001$ \\
\hline ССВ & $5(83.3 \%)$ & $25(62.5 \%)$ & $24(75.0 \%)$ & 0.45 \\
\hline Diuretic & $1(16.7 \%)$ & $7(17.5 \%)$ & $12(37.5 \%)$ & 0.14 \\
\hline Vasodilator & $0(0.0 \%)$ & $9(22.5 \%)$ & $6(18.8 \%)$ & 0.63 \\
\hline $\begin{array}{l}\text { Dialyzable antihypertensive } \\
\text { meds }\end{array}$ & $4(57.1 \%)$ & $20(54.1 \%)$ & $20(64.5 \%)$ & 0.74 \\
\hline $\begin{array}{l}\text { Erythropoietin Dose/week } \\
\text { (units/wk) }\end{array}$ & $2267[1367,4825]$ & $2167[821,3425]$ & $1500[120,3750]$ & 0.66 \\
\hline Sodium (mEq/L) & $140(2.8)$ & $139(3.1)$ & $139(3.9)$ & 0.64 \\
\hline Potassium (mEq/L) & $4.5(0.3)$ & $4.7(0.6)$ & $4.6(0.7)$ & 0.57 \\
\hline Creatinine $(\mathrm{mg} / \mathrm{dl})$ & $10.6(3.3)$ & $9.6(2.6)$ & $9.0(3.4)$ & 0.41 \\
\hline Calcium (mg/dl) & $8.7(0.5)$ & $9.1(0.6)$ & $8.9(0.8)$ & 0.27 \\
\hline Phosphorus (mg/dl) & $5.0(1.9)$ & $5.9(2.0)$ & $5.7(2.0)$ & 0.51 \\
\hline Albumin (mg/dl) & $4.0(0.4)$ & $3.9(0.4)$ & $3.9(0.3)$ & 0.84 \\
\hline Hematocrit (\%) & $33.9(6.9)$ & $35.3(2.8)$ & $34.6(2.9)$ & 0.47 \\
\hline Single pool Kt/V & $1.5(0.2)$ & $1.7(0.2)$ & $1.6(0.4)$ & 0.51 \\
\hline Dialysate sodium $(\mathrm{mEq} / \mathrm{L})$ & $139(1.5)$ & $138(1.8)$ & $139(2.1)$ & 0.80 \\
\hline $\begin{array}{l}\text { Dialysate Serum Sodium } \\
\text { gradient }(\mathrm{mEq} / \mathrm{L})\end{array}$ & $-1.0[-3.0 ; 0.0]$ & $0.0[-3.1 ; 2.3]$ & $0.0[-4.0 ; 2.0]$ & 0.77 \\
\hline Dialysate calcium (mEq/L) & $2.6(0.5)$ & $2.4(0.3)$ & $2.5(0.3)$ & 0.30 \\
\hline $\begin{array}{l}\text { Dialysate serum Calcium } \\
\text { gradient (meq/L) }\end{array}$ & $-3.6(1.0)$ & $-4.2(1.0)$ & $-3.9(0.9)$ & 0.11 \\
\hline
\end{tabular}

Table 2. Cardiac MRI characteristics among the 3 groups. ${ }^{*} \mathrm{LVH}$ defined as LVMI $\geq 45 \mathrm{~g} / \mathrm{m}$-height for women and $\geq 49 \mathrm{~g} / \mathrm{m}$-height for men. \# LV concentricity defined as LV mass/LVEDV ^ 0.67

\begin{tabular}{|c|c|c|c|c|}
\hline Cardiac MRI variable & $\begin{array}{l}\text { SBP Increased } \geq 10 \mathrm{mmHg} \\
(\mathrm{N}=7) \\
\text { Mean (SD) or } \mathrm{n}(\%)\end{array}$ & $\begin{array}{c}\text { SBP Decreased } \geq 10 \mathrm{mmHg} \\
(\mathrm{N}=40) \\
\text { Mean }(\mathrm{SD}) \text { or } \mathrm{n}(\%)\end{array}$ & $\begin{array}{l}\text { SBP Unchanged +/- } 10 \mathrm{mmHg} \\
(\mathrm{N}=33) \\
\text { Mean (SD) or } \mathrm{n}(\%)\end{array}$ & P value \\
\hline LV Mass (g) & $188.4(75.7)$ & $143.6(43.1)$ & $154.8(44.5)$ & 0.07 \\
\hline LV Mass Index $\left(\mathrm{g} / \mathrm{m}^{2}\right)$ & $41.0(12.6)$ & $35.9(10.2)$ & $37.4(8.7)$ & 0.43 \\
\hline LV hypertrophy* & $2(28.6 \%)$ & $5(12.5 \%)$ & $4(12.1 \%)$ & 0.43 \\
\hline LV concentricity $\left(\mathrm{g} / \mathrm{mL}^{0.67}\right)^{\#}$ & $4.8(0.9)$ & $4.4(1.0)$ & $4.5(1.0)$ & 0.68 \\
\hline LV End-Diastolic Volume (ml) & $236(97.0)$ & $181(52.0)$ & $200(60.0)$ & 0.07 \\
\hline LV End-Systolic Volume (ml) & $123(74.6)$ & $86.7(45.4)$ & $99.1(40.6)$ & 0.14 \\
\hline LV Ejection Fraction (\%) & $51.3(11.9)$ & $54.3(12.6)$ & $51.3(8.8)$ & 0.47 \\
\hline
\end{tabular}




\section{Kidney Blood Pressure Research}

Kidney Blood Press Res 2018;43:882-892

DOI: $10.1159 / 000490336$

Published online: 5 June, 2018

(C) 2018 The Author(s). Published by S. Karger AG, Basel

Shamir et al.: Intradialytic Hypertension and Left Ventricular Mass
Cardiac structural and functional measures

The cardiac parameters in 3 groups are shown in Table 2 . In unadjusted analyses, there was no significant difference in LVMI among the 3 groups (Fig. 2). Four $(11.8 \%)$ of women and $7(15.2 \%)$ of men had left ventricular hypertrophy (LVH). The distribution of LVH was/was not significantly different in the 3 groups ( $\mathrm{p}=0.43$ ). We did not find any difference in $\mathrm{LV}$ concentricity among the 3 groups. Moreover, none of the patients in our cohort had concentric hypertrophy suggestive of diastolic dysfunction, as defined by the cutoff thresholds by Khouri et al. [17].

In multivariable regression analyses, IDH was significantly associated with an increased LVMI relative to the SBP decreased group $(\beta$ [95\% confidence interval $(\mathrm{CI})]$ $=12.5[3.6,21.5], \mathrm{p}=0.01)$ after adjusting for age, sex, diabetes, IDWG\%, pre-HD SBP and beta blocker use (Table 3 and Fig. 3). Also, a rise or drop in $\mathrm{BP}<10 \mathrm{~mm}$ $\mathrm{Hg}$ during HD was associated with increased LVMI ( $\beta$ [95\% confidence interval $(\mathrm{CI})]=6.4[0.9,11.9], \mathrm{p}=0.03)$. The regression model explained $20 \%$ of the variance in LVMI (adjusted $\mathrm{R}^{2}=0.2$ ). Pre-HD SBP was also significantly associated with LVMI ( $\beta$ [95\% confidence interval $(\mathrm{CI})]=0.3[0.2,0.5], \mathrm{p}<0.001)$ in adjusted analysis. In adjusted models, when $\triangle \mathrm{SBP}$ was modeled as a continuous variable, every $1 \mathrm{~mm}$ rise in $\triangle \mathrm{SBP}$ during HD was associated with $0.2 \mathrm{~g} / \mathrm{m}^{2}$ increase in LVMI after adjusting for age, sex, diabetes, IDWG\%, pre-HD SBP and beta blocker use ( $p=0.04)$ (Fig. 4). Since RAASi may have effect on cardiac remodeling, we conducted additional regression analysis adjusting for RAASi use, and this did not significantly alter our results (data not shown).

\section{Sensitivity Analyses}

Using the definition that has been used in some of the prior studies i.e. $\Delta \mathrm{SBP} \geq 10 \mathrm{mmHg}$ during HD in at least 4 of 6 HD treatments, $6(7.5 \%)$ of the patients had IDH. There was no association of IDH by this definition and LVMI ( $\mathrm{p}=0.44)$.

We also categorized patients based on the proportion of dialysis treatments with $\triangle \mathrm{SBP}$ $\geq 10 \mathrm{mmHg}$ during HD in a 1 month period. Fifty-nine (74\%) patients had $\Delta \mathrm{SBP} \geq 10 \mathrm{~mm} \mathrm{Hg}$ in $0-25 \%$ of HD treatments, 17 (21\%) experienced this in $>25 \%$ to $50 \%$ of HD treatments, 3 $(4 \%)$ in $>50 \%$ to $75 \%$ of HD treatments, and only 1 patient had this in $>75 \%$ of HD treatments. There was no significant association between quartiles of proportion of HD treatments with $\Delta \mathrm{SBP} \geq 10 \mathrm{~mm}$ Hg and LVMI $(\mathrm{p}=0.65)$. Additional sensitivity analysis using $\Delta \mathrm{SBP}$ cutoff of $+/-$ $5 \mathrm{~mm} \mathrm{Hg}$, instead of $+/-10 \mathrm{~mm} \mathrm{Hg}$ revealed no significant association between the 3 patient groups and any of the cardiac MRI characteristics. 


\section{Kidney Blood Pressure Research}

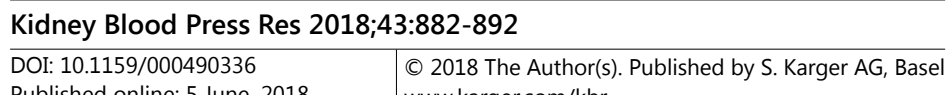

Published online: 5 June, 2018 www.karger.com/kb

Shamir et al.: Intradialytic Hypertension and Left Ventricular Mass

Fig. 3. Multivariable adjusted association of change in systolic blood pressure during hemodialysis and left ventricular mass index in the 3 groups*. *Adjusted for age, sex, diabetes, IDWG\%, pre-HD SBP and beta blocker use.

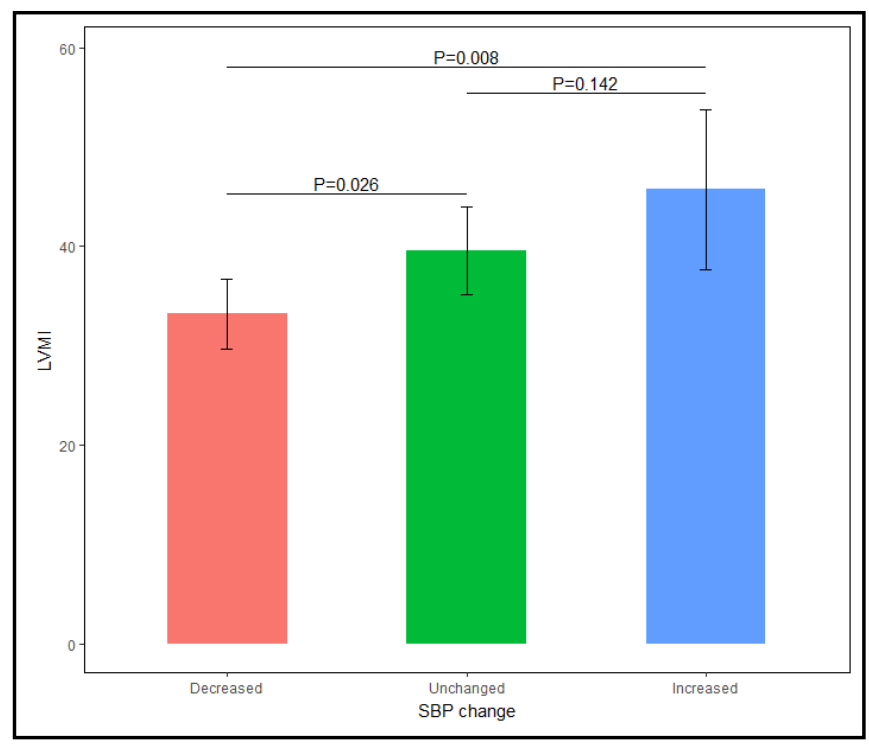

Fig. 4. Multivariable adjusted association of change in systolic blood pressure (as a continuous variable) during hemodialysis and left ventricular mass index*. *Adjusted for age, sex, diabetes, IDWG\%, pre-HD SBP and beta blocker use.

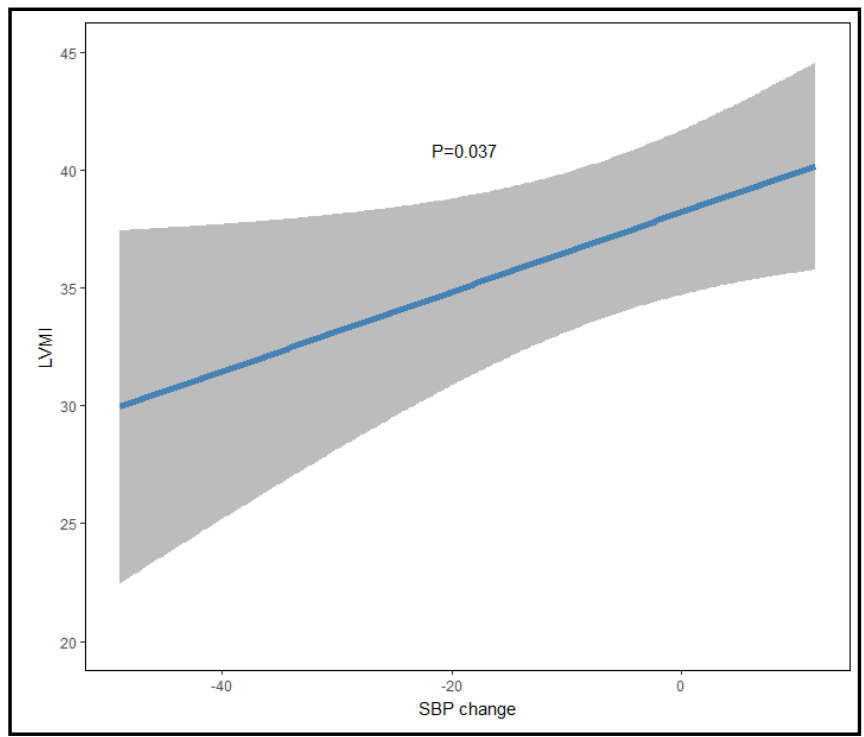

\section{Discussion}

Intradialytic hypertension is a well-known but under recognized entity in HD patients $[2,3]$. It is associated with poor clinical outcomes including increased morbidity and mortality, however the exact mechanisms are poorly understood [5, 6]. Our study identified a significant independent association of IDH with left ventricular mass index as measured by cardiac MRI in HD patients, providing insights into potential mechanism by which IDH may lead to adverse outcomes.

Association of IDH with adverse clinical outcomes is well established. Inrig et al. showed that among prevalent HD patients, those with $\triangle \mathrm{SBP} \geq 10 \mathrm{~mm} \mathrm{Hg}$ during $\mathrm{HD}$ had a 2-times higher odds of hospitalization or death at 6 months compared to subjects whose SBP fell during HD [6]. They further demonstrated a similar finding in incident HD patients, in whom every $10 \mathrm{mmHg}$ increase in SBP during HD was independently associated with a 6\% increased hazard of death at 2-year follow up (HR 1.06, CI 1.01-1.11) [5]. In fact, a recent observational 


\section{Kidney Blood Pressure Research} Kidney Blood Press Res 2018;43:882-892
\begin{tabular}{l|l} 
DOI: 10.1159/000490336 & $\begin{array}{l}\text { c } 2018 \text { The Author(s). Published by S. Karger AG, Basel } \\
\text { www.karger.com/kbr }\end{array}$ \\
\hline Published online: 5 June, 2018 &
\end{tabular}

Shamir et al.: Intradialytic Hypertension and Left Ventricular Mass

study of more than 100, $000 \mathrm{HD}$ patients showed that any rise in systolic BP over $0 \mathrm{~mm}$ Hg during HD was associated with higher mortality, thus emphasizing the importance of IDH [21]. Our study provides a plausible mechanistic explanation for increased mortality in these patients by showing an association of IDH with increased LVMI as LVMI has been shown to be a strong and independent predictor of survival and cardiovascular events in HD patients $[12,14]$. However, it is important to note that we did not look at cardiovascular morbidity or mortality as an outcome in this study. Thus, although our findings demonstrate an association of IDH and a well-known cardiovascular risk factor, we cannot directly conclude that IDH is associated with poor outcomes because of LVH. Additionally, IDH and left ventricular hypertrophy may share common underlying pathophysiological mechanisms such as extracellular volume overload and increased peripheral vascular resistance due to endothelial dysfunction [1, 7-11]. IDH has also been associated with increased ambulatory blood pressure in HD patients, which may in turn accentuate LVH [4]. Recent studies show regression of LVM with intensive and frequent dialysis [22, 23]. It is plausible that aggressive management of IDH may also prevent increases in LVM.

Among the potential mechanisms for IDH, extracellular volume overload has been implicated as one of the most important ones [1]. Using bioimpedance spectroscopy, patients with IDH have been demonstrated to have higher volume overload [24]; and aggressive dry weight lowering has been shown to modify the intradialytic BP slope [9]. However surprisingly, consistent with prior studies, we found that patients with IDH had lower pre HD SBP and lower IDWG\% as compared to those without IDH $[6,21]$. This counterintuitive finding in multiple studies begs further exploration $[5,6,21]$. It may be that although these patients have lower IDWG\%, they are still intravascularly volume overloaded. And lower IDWG and normal pre HD SBP may mislead towards lower ultrafiltration goals, thus contributing to volume overload. In fact, it has been shown that patients with recurrent IDH have higher post-dialysis extracellular volume as measured by bioimpedance analysis [25]. Additionally, in a study of more than $500 \mathrm{HD}$ patients, the post HD extracellular water overhydration (in liters) was shown to be significantly greater in the IDH group [0.7 (0.17 to 1.1) liter] as compared to stable [0.39 (-0.2 to 0.95) liter] and fall in BP groups [0.38 (-0.19 to 0.86) liter] [26]. Additionally, inappropriate increase in renin-angiotensin or sympathetic nervous system activity or endothelial response triggered by small decrements in intravascular volume during ultrafiltration on HD in these patients may also play a role in IDH, as demonstrated by increased intradialytic total peripheral resistance in these patients $[6,8,25,27]$.

Another potential cause of IDH is thought to be dialysate serum sodium gradient, and a more positive gradient (i.e. net intradialytic sodium gain) has been associated with IDH $[10,28]$. However, we did not find any significant differences in sodium gradient in the 3 groups in our study. The average sodium gradient was only $0.5 \pm 3.5 \mathrm{meq} / \mathrm{L}$ as compared to previous studies which showed a positive association with IDH (3.5-5 meq/L) and thus may explain this negative finding $[10,28]$. Antihypertensive medications may play a role in IDH. One possible mechanism is y due to dialyzability of water soluble medications during HD [11]. However, in our study there was no difference in use of dialyzable antihypertensive medications among those with IDH as compared to those without. RAASi may mitigate effect of renin on HTN and prevent IDH, but their use was similar in the 3 groups in our study. There is also limited evidence supporting role of carvedilol in improving endothelial function and potentially decreasing the risk for IDH [8]. Although we did find that patients with IDH had less beta blocker use as compared to those with unchanged BP during HD, our conclusions are limited given the small sample size in our study. Lastly, calcium channel blockers (CCBs) may cause peripheral vasodilatation and thus volume overload and IDH. However, in contrast to Sebastian et al. we did not find any association of IDH with CCBs [24].

The prevalence of IDH in our study was $8.6 \%$ which is similar to that reported in other studies that have used multiple months BP data to define IDH $[21,29]$. This is in contrast to $12-28 \%$ prevalence reported in some studies that have used BP data from only 3-6 HD 


\section{Kidney Blood Pressure Research}

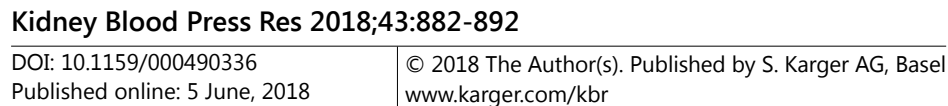

Shamir et al.: Intradialytic Hypertension and Left Ventricular Mass

sessions $[5,6,24]$. This suggests that there may be wide variability in change in SBP during $\mathrm{HD}$ and regression to mean by using BP data over longer time periods may help to decrease false positive rates of IDH. Also, since patients with IDH tend to have lower pre-HD SBP, as shown in ours and prior studies [5, 21], they may have not met eligibility criteria for our study which only enrolled hypertensive patients. Interestingly, we found that patients with IDH were less likely to be diabetic as compared to the other two groups. However, we cannot be sure whether this is due to the small number of patients with IDH in our study or due to plausible role of underlying autonomic dysfunction and impaired peripheral vascular resistance in diabetes, leading to lack of rise of SBP during HD in patients without IDH.

Strengths of our study include use of averaged blood pressure data from 1 month period to identify IDH, detailed antihypertensive medication data, detailed dialysate prescription data, and evaluation of LVMI using centrally read cardiac MRIs. However, our findings should be considered in light of several limitations. Firstly, we used routine dialysis unit BP, which may not have been taken using standard BP measurement guidelines. However, we captured BP from all treatments over a 1 month period, instead of $\leq 2$ weeks data as done in most prior studies, thus decreasing measurement error and the potential impact of outliers [46]. Moreover, routine dialysis BP measures are more practically applicable in the clinical setting. Secondly, since we used BP readings prior to BID enrollment, there was an average of $2.1 \pm 0.8$ months time lapse between the baseline BP readings and the cardiac MRI. During this baseline time period, BP management changes may have been implemented per the BID study protocol. However, given the short duration, it is unlikely that the BP changes in this time period had an effect on LVM. Thirdly, we did not have information on measured dialysate sodium in our study, which may be significantly different from prescribed dialysate sodium, as shown in a study of $>300$ hemodialysis patients [30]. Fourthly, since this is a crosssectional, we cannot establish causality and may have not accounted for other unmeasured confounders. Fifth, only 7 (8.6\%) patients in our cohort had IDH, and may not reflect characteristics of the larger HD population with IDH, thus limiting the generalizability of our findings. Lastly, the cohort utilized for this analysis was part of a randomized controlled trial, which excluded "sicker patients" such as those prone to intradialytic hypotension requiring hospitalizations or who had contraindications to MRI (cardiac pacemaker, etc.), or those who were not hypertensive based on pre dialysis SBP, which likely underestimated our results.

\section{Conclusion}

Intradialytic hypertension in HD patients is associated with increased left ventricular mass index, and may contribute to their increased cardiovascular morbidity and mortality. Identifying patients with IDH may help clinicians to risk stratify high risk patients, and aggressively target IDH lowering strategies such as aggressive volume control in this population.

\section{Acknowledgements}

Sources of Support: This work was supported by National Institute of Diabetes and Digestive and Kidney Diseases Grant P30-DK-079307, R01-DK083424-01 (Zager), American Heart Association grant 11FTF7520014 (Jhamb) and Dialysis Clinic, Inc. (DCI). DCI had no role in interpretation of data.

The content is solely the responsibility of the authors and does not necessarily represent the official views of the National Institutes of Health. 


\section{Kidney \\ Blood Pressure Research}

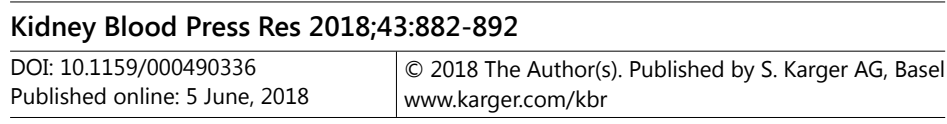

Shamir et al.: Intradialytic Hypertension and Left Ventricular Mass

\section{Disclosure Statement}

The authors of this manuscript have no conflicts of interest to disclose.

\section{References}

1 Van Buren PN, Inrig JK: Mechanisms and Treatment of Intradialytic Hypertension. Blood Purif 2016;41:188-193.

-2 Inrig JK: Intradialytic hypertension: a less-recognized cardiovascular complication of hemodialysis. Am J Kidney Dis 2010;55:580-589.

- Locatelli F, Cavalli A, Tucci B: The growing problem of intradialytic hypertension. Nat Rev Nephrol 2010;6:41-48.

4 Van Buren PN, Kim C, Toto R, Inrig JK: Intradialytic Hypertension and the Association with Interdialytic Ambulatory Blood Pressure. Clinical Journal of the American Society of Nephrology 2011;6:1684-1691.

-5 Inrig JK, Patel UD, Toto RD, Szczech LA: Association of blood pressure increases during hemodialysis with 2-year mortality in incident hemodialysis patients: a secondary analysis of the Dialysis Morbidity and Mortality Wave 2 Study. Am J Kidney Dis 2009;54:881-890.

6 Inrig JK, Oddone EZ, Hasselblad V, Gillespie B, Patel UD, Reddan D, Toto R, Himmelfarb J, Winchester JF, Stivelman J, Lindsay RM, Szczech LA: Association of intradialytic blood pressure changes with hospitalization and mortality rates in prevalent ESRD patients. Kidney Int 2007;71:454-461.

7 Raj DS, Vincent B, Simpson K, Sato E, Jones KL, Welbourne TC, Levi M, Shah V, Blandon P, Zager P, Robbins RA: Hemodynamic changes during hemodialysis: role of nitric oxide and endothelin. Kidney Int 2002;61:697-704.

-8 Inrig JK, Van Buren P, Kim C, Vongpatanasin W, Povsic TJ, Toto R: Probing the mechanisms of intradialytic hypertension: a pilot study targeting endothelial cell dysfunction. Clin J Am Soc Nephrol 2012;7:13001309.

9 Agarwal R, Light RP: Intradialytic hypertension is a marker of volume excess. Nephrol Dial Transplant 2010;25:3355-3361.

10 Inrig JK, Molina C, D'Silva K, Kim C, Van Buren P, Allen JD, Toto R: Effect of low versus high dialysate sodium concentration on blood pressure and endothelial-derived vasoregulators during hemodialysis: a randomized crossover study. Am J Kidney Dis 2015;65:464-473.

11 Inrig JK: Antihypertensive agents in hemodialysis patients: a current perspective. Seminars in dialysis 2010;23:290-297.

12 Zoccali C, Benedetto FA, Mallamaci F, Tripepi G, Giacone G, Stancanelli B, Cataliotti A, Malatino LS: Left ventricular mass monitoring in the follow-up of dialysis patients: Prognostic value of left ventricular hypertrophy progression. Kidney Int 2004;65:1492-1498.

13 Gul A, Miskulin D, Gassman J, Harford A, Horowitz B, Chen J, Paine S, Bedrick E, Kusek JW, Unruh M, Zager P: Design of the Blood Pressure Goals in Dialysis pilot study. Am J Med Sci 2014;347:125-130.

14 Zoccali C, Benedetto FA, Mallamaci F, Tripepi G, Giacone G, Cataliotti A, Seminara G, Stancanelli B, Malatino LS, Investigators C: Prognostic impact of the indexation of left ventricular mass in patients undergoing dialysis. J Am Soc Nephrol 2001;12:2768-2774.

15 Lang RM, Bierig M, Devereux RB, Flachskampf FA, Foster E, Pellikka PA, Picard MH, Roman MJ, Seward J, Shanewise JS, Solomon SD, Spencer KT, Sutton MS, Stewart WJ, Chamber Quantification Writing Group, American Society of Echocardiography's Guidelines and Standards Committee, European Association of Echocardiography: Recommendations for chamber quantification: a report from the American Society of Echocardiography's Guidelines and Standards Committee and the Chamber Quantification Writing Group, developed in conjunction with the European Association of Echocardiography, a branch of the European Society of Cardiology. J Am Soc Echocardiogr 2005;18:1440-1463.

16 Shah AM: Ventricular remodeling in heart failure with preserved ejection fraction. Current heart failure reports 2013;10:341-349. 


\section{Kidney \\ Blood Pressure Research}

Kidney Blood Press Res 2018;43:882-892

\begin{tabular}{l|l}
\hline DOI: $10.1159 / 000490336$ & (c) 2018 The Author(s). Published by S. Karger AG, Basel
\end{tabular}

Published online: 5 June, 2018 www.karger.com/kbr

17 Khouri MG, Peshock RM, Ayers CR, de Lemos JA, Drazner MH: A 4-tiered classification of left ventricular hypertrophy based on left ventricular geometry: the Dallas heart study. Circ Cardiovasc Imaging 2010;3:164-171.

18 Muggeo VM: Estimating regression models with unknown break-points. Stat Med 2003;22:3055-3071.

19 Wickham H, Francois R. dplyr: A Grammar of Data Manipulation. R package version 0.5.0. https://CRAN.R-project.org/package=dplyr.

20 R Core Team. R: A language and environment for statistical computing. R Foundation for Statistical Computing V, Austria. https://www.R-project.org/.

-21 Park J, Rhee CM, Sim JJ, Kim YL, Ricks J, Streja E, Vashistha T, Tolouian R, Kovesdy CP, Kalantar-Zadeh K: A comparative effectiveness research study of the change in blood pressure during hemodialysis treatment and survival. Kidney Int 2013;84:795-802.

-22 Culleton BF, Walsh M, Klarenbach SW, Mortis G, Scott-Douglas N, Quinn RR, Tonelli M, Donnelly S, Friedrich MG, Kumar A, Mahallati H, Hemmelgarn BR, Manns BJ: Effect of frequent nocturnal hemodialysis vs conventional hemodialysis on left ventricular mass and quality of life: a randomized controlled trial. JAMA 2007;298:1291-1299.

23 Chan CT, Chertow GM, Daugirdas JT, Greene TH, Kotanko P, Larive B, Pierratos A, Stokes JB: Effects of daily hemodialysis on heart rate variability: results from the Frequent Hemodialysis Network (FHN) Daily Trial. Nephrol Dial Transplant 2014;29:168-178.

24 Sebastian S, Filmalter C, Harvey J, Chothia MY: Intradialytic hypertension during chronic haemodialysis and subclinical fluid overload assessed by bioimpedance spectroscopy. Clin Kidney J 2016;9:636-643.

25 Van Buren PN, Zhou Y, Neyra JA, Xiao G, Vongpatanasin W, Inrig J, Toto R: Extracellular Volume Overload and Increased Vasoconstriction in Patients With Recurrent Intradialytic Hypertension. Kidney Blood Press Res 2016;41:802-814.

-26 Nongnuch A, Campbell N, Stern E, El-Kateb S, Fuentes L, Davenport A: Increased postdialysis systolic blood pressure is associated with extracellular overhydration in hemodialysis outpatients. Kidney Int 2015;87:452-457.

27 Cirit M, Akcicek F, Terzioglu E, Soydas C, Ok E, Ozbasli CF, Basci A, Mees EJ: 'Paradoxical' rise in blood pressure during ultrafiltration in dialysis patients. Nephrol Dial Transplant 1995;10:1417-1420.

28 Movilli E, Camerini C, Gaggia P, Zubani R, Feller P, Poiatti P, Pola A, Carli O, Valzorio B, Cancarini G: Role of dialysis sodium gradient on intradialytic hypertension: an observational study. Am J Nephrol 2013;38:413419.

29 Van Buren PN, Kim C, Toto RD, Inrig JK: The prevalence of persistent intradialytic hypertension in a hemodialysis population with extended follow-up. Int J Artif Organs 2012;35:1031-1038.

30 Gul A, Miskulin DC, Paine SS, Narsipur SS, Arbeit LA, Harford AM, Weiner DE, Schrader R, Horowitz BL, Zager PG: Comparison of Prescribed and Measured Dialysate Sodium: A Quality Improvement Project. Am J Kidney Dis 2016;67:439-445. 